\title{
EDITORIAL \\ Spine professionals must critically examine the impact of medicolegal pressures on delivering care
}

\author{
Daniel M. Sciubba, MD \\ Department of Neurological Surgery, Johns Hopkins Medical Center, Baltimore, Maryland
}

$\mathbf{J}$ OURNAL of Neurosurgery: Spine and other journals like it have sought to disseminate basic science and clinical research, case reports, and editorials related to spine care in an effort to educate, inspire, and advocate for those involved in spine care. The majority of such articles focus on diagnosis, treatment, and clinical outcomes in providing such care. More recently, articles focusing on subjects outside of basic science or clinical data have become increasingly popular, investigating topics such as economic analyses of providing care, changes to the training of specialists, and the need for providers to show objective measures to third party payers regarding value of care. Such articles have likely been inspired by the need for providers to become involved in the larger world of spine care organization, implementation, and access in order to provide care while still responding to financial, administrative, governmental, and legal pressures. ${ }^{6}$ Unfortunately, despite the increased attention paid to issues considered to be on the periphery of traditional academic spine discussions, there remains a relative dearth of studies examining the interaction of the spine field with the legal system, which indubitably impacts all stakeholders, especially in countries such as the United States. ${ }^{2,3,5}$

In their article, "Malpractice litigation following spine surgery," Daniels and colleagues provide a timely and relevant look at some data surrounding medical malpractice suits involving spine care. ${ }^{1}$ After positing that few studies have evaluated the association between spine surgical complications and medical malpractice proceedings, outcomes, and awards, they sought "to identify the most frequent causes of alleged malpractice in spine surgery and gain insight into patient demographic and clinical characteristics associated with medical negligence litigation."

Using the VerdictSearch (ALM Media Properties, LLC) medicolegal research service, Daniels et al. analyzed the demographic data of "spine surgery" cases. Searching for cases between 1988 and 2015, they were able to successfully analyze 234 cases and found that $54.2 \%$ (127 cases) resulted in a defendant ruling, $26.1 \%$ (61) in a plaintiff ruling, and $19.6 \%$ (46) in a settlement. The awards granted for plaintiff rulings ranged from $\$ 134,000$ to $\$ 38,323,196$ (mean \$4,045,205 $\pm \$ 6,804,647$ ), while the awards for settlements ranged from $\$ 125,000$ to $\$ 9,000,000$ (mean $\$ 1,930,278 \pm \$ 2,113,593 ; \mathrm{p}=0.022$ ). Further analysis revealed that cases with a delay in diagnosis of the complication were more likely to result in a plaintiff verdict or settlement $(42.9 \%$ vs $72.7 \%, \mathrm{p}=0.007)$ than a defense verdict, and were more likely to settle out of court $(17.5 \%$ vs $40.9 \%, p=0.008)$. Interestingly, a "catastrophic complication" occurred in $28 \%(66 / 234)$ of the cases studied, and in such cases, physicians were more likely to lose the case (plaintiff verdict or settlement; $66.7 \%$ vs $37.5 \%$, p < 0.001 ), and mean awards were significantly larger than those for noncatastrophic complications $(\$ 6.1 \mathrm{M}$ vs $\$ 2.9 \mathrm{M}$, $\mathrm{p}=0.04$ ). Of note, the medical specialty of the provider (neurosurgery, orthopedic surgery, or nonsurgical specialty) and the age or sex of the patient were not associated with the case outcome or the award granted $(\mathrm{p}>0.05)$. Finally, they commented that the average time to decision for defendant verdicts was 5.1 years; for plaintiff rulings, 5.0 years; and for settlements, 3.4 years.

In the process of providing effective spine care to patients, providers are being forced to function in a setting where factors are constantly conflicting with one another: patient safety versus efficiency, access to care versus cost of care, training new surgeons versus providing the highest level of expertise, and so on. The legal system, especially in the United States, represents a microcosm of these conflicting pressures. The ideal golden mean would be a legal system-medical system interplay that could provide patient safety via the identification and correction of abuses and the successful employment of quality control, 
while avoiding burdensome economic damages to providers and hospitals as well as expensive preventive measures employed to avoid lawsuits. ${ }^{4}$

All stakeholders involved in spine care, including patients, providers, hospitals, third-party payers, medical device and pharmaceutical companies, malpractice insurance companies, and governments, are being forced to look at both sides of each dynamic. Currently, each party has "budgeted in" the cost of potential or actual medicolegal involvement. Providers pay premiums for medical malpractice coverage largely derived from trends in recent legal payouts and settlements. Hospitals, in addition to paying for malpractice coverage, also employ large legal teams to monitor and manage legal issues and reserve large sums of money allocated for unexpected catastrophic legal rulings. Medical device and pharmaceutical companies and malpractice insurance providers account in part for potential or active legal costs by passing down the cost to the consumer via the price of their products. As a result, there is no doubt that the contribution of costs from medicolegal issues to the overall rise in health care costs is substantial.

The current work of Daniel et al. is especially relevant. The unsustainable rate of growth of health care costs is multifactorial: an aging and sicker population, increased access to high-cost care, and technological advances. However, the medicolegal cost drivers have not been adequately examined. The authors' paper not only serves to provide some basic data on spine surgery lawsuits, but may also inspire readers to conduct deeper research into models that can provide patient safety with less burdensome financial ramifications on the system. In light of the change in governmental administration in the United States following recent elections, there will undoubtedly be renewed interest on all sides regarding issues such as tort reform, safe clearance of medical devices through the Food and Drug Administration, and government funding of research organizations such as the National Institutes of Health. Hopefully, we as a field will begin to more thoroughly examine how health care costs versus patient safety and access can be modeled to account for all sides. The authors comment that their limited data set clearly does not represent all spine surgery malpractice cases. Only by integrating comprehensive data from providers, hospitals, insurers, and legal sources can the picture become clearer. https://thejns.org/doi/abs/10.3171/2017.1.SPINE161371

\section{References}

1. Daniels AH, Ruttiman R, Eltorai AEM, DePasse JM, Brea BA, Palumbo MA: Malpractice litigation following spine surgery. J Neurosurg Spine [epub ahead of print July 21, 2017. DOI: 10.3171/2016.11.SPINE16646]
2. Epstein NE: A review of medicolegal malpractice suits involving cervical spine: what can we learn or change? J Spinal Disord Tech 24:15-19, 2011

3. Fager CA: Professional liability and potential liability. Neurosurgery 16:866-872, 1985

4. Li S, Dor A, Deyo D, Hughes DR: The impact of state tort reforms on imaging utilization. J Am Coll Radiol 14:149-156, 2017

5. Quigley RS, Akpolat YT, Forrest BD, Wongworawat MD, Cheng WK: Reason for lawsuit in spinal cord injury affects final outcome. Spine (Phila Pa 1976) 11:851-855, 2015

6. Woolhandler S, Himmelstein DU: Administrative work consumes one-sixth of U.S. physicians' working hours and lowers their career satisfaction. Int J Health Serv 44:635-642, 2014

\section{Disclosures}

Dr. Sciubba is a consultant for DePuy Synthes, Medtronic, Globus, and Stryker.

\section{Response}

\section{Alan H. Daniels, MD}

Department of Orthopaedic Surgery, Brown University Warren Alpert Medical School/Rhode Island Hospital, Providence, Rhode Island

Dr. Sciubba has provided a thoughtful and thorough review of our article. In particular, we appreciate his proclamation of the stakeholders involved in the spine medicolegal industry, which includes not only obviously affected patients, physicians, and lawyers, but also the government, malpractice insurers, and third-party payers, as well as the medical device and pharmaceutical industries. As Dr. Sciubba highlights, these parties have a vested interest in examining the reasons for malpractice litigation following spine surgery and in keeping the burden of medicolegal expenses down, as they represent an important cost in the overall cost of health care in the United States, especially when defensive medicine costs are factored in. ${ }^{1}$

Although our investigation barely scratches the surface of the problem by examining only 234 alleged malpractice cases, it does provide an important stepping-off point to initiate future larger studies that can help to explore this issue affecting all spine patients and care providers. We are hopeful that future studies can also examine larger data sets to describe trends over geography and time and explore the effect of tort reform and caps on litigation following spine surgery.

\section{References}

1. Reschovsky JD, Saiontz-Martinez CB: Malpractice claim fears and the costs of treating Medicare patients: a new approach to estimating the costs of defensive medicine. Health Serv Res [epub ahead of print], 2017 